\title{
EDITORIAL
}

\section{Should teens be allowed to consent for vaccines?}

\author{
John D. Lantos
}

Doi: doi.org/10.53685/jshmdc.v2i1.21

In order to achieve herd immunity against COVID-19, teens and children will need to be vaccinated. Most countries do not allow teens to consent for medical treatment, including immunizations. However, as noted by the World Health Organization, countries can mandate vaccines. Furthermore, "When mandatory vaccination is established in relevant provisions in law, consent may not be required"1.

COVID-19 vaccines are now available for teens. Some teens want to be immunized against COVID. Most parents are eager to have their teens immunized. But some are hesitant about vaccines in general and the COVID vaccine in particular. This raises a fundamental question about the legal and ethical status of adolescents. The question has been asked in the past about other vaccines. Should teens be allowed to consent to immunization even if their parents object?

The situation in different countries requires doctors to be attentive to and compliant with the relevant laws in their jurisdiction. In the United States, there is no federal law regarding this complex issue. Instead, each state makes its own policies regarding immunizations and public health. It may be relevant for other countries to understand the variation in laws in different states in the United States since they illustrate a range of possible responses to the question of whether teens should be allowed to consent to immunization.

Before COVID came along, there were vigorous debates about whether teens should be legally permitted to consent to immunizations. In those pre-COVID days, the debates focused on teens whose vaccine-hesitant parents had refused routine childhood immunizations ${ }^{2}$. For example, some teens wanted the measles vaccine even after their parents had chosen not to have them immunized as children. The parents may have feared that measles would cause autism, even the connection between the two has been thoroughly debunked. As another example, there have been debates about whether teens should be able to consent for the vaccine against the human papilloma virus (HPV) ${ }^{3}$.

Many public health experts and bioethicists argue that teens should be allowed to consent. The arguments are straightforward. Vaccines are safe and effective, medically recommended, and good for both the individual and the community. In spite of these powerful arguments, the law lags behind.

In the United States, laws in most states do not allow teens to consent for medical treatments. Instead, parents must give permission. There are some exceptions. Laws in every state permit minors to make clinical decisions regarding certain sensitive or stigmatized health care services, such as those related to sexual health, reproduction, mental health and substance use disorders ${ }^{4}$. These laws promise teens confidentiality and empower them to seek and use health care services.

Some states allow teens to consent to not just treatments related to reproductive health but also to immunizations if the vaccine is plausibly related to reproductive health ${ }^{5}$. California, Illinois and New York allow adolescents to consent to hepatitis B and HPV vaccines. They must have parental consent to receive all other vaccinations. 
Some states go further. In Idaho, minors of any age do not need parental consent for any health care services, including vaccines, if the provider determines the minor possesses "requisite comprehension." Washington D.C. allows minors to consent to vaccination if the health care provider determines the minor meets the standard for informed consent. Alabama, Oregon, Alaska and South Carolina permit adolescents to make their own clinical decisions about vaccination (Alabama at 14 years of age, Oregon at 15, and South Carolina at 16).

The COVID situation is complicated by a few factors. On the one hand, there is great perceived urgency. The pandemic has made many conventional understandings of law and ethics feel inadequate. The need to end the pandemic grounds arguments for immunizing as many people as we can, as quickly as possible, even if it means overturning long-standing legal traditions. But it isn't that easy. The current laws are still in force. The COVID vaccine clearly does not fall under the usual carve-outs for mental health care or reproductive health care. Furthermore, the vaccines have still not been fully approved by the Food and Drug Administration.

How urgent is the need? That is difficult to quantify. Most parents want their teens to be immunized. Most vaccine-hesitant parents ultimately agree to vaccination. Furthermore, teens who get COVID generally have mild cases. They can, however, transmit the disease to higher risk adults and so become vectors for more serious illness than they experience themselves.

For now, the law in most states does not permit teens to consent to the COVID-19 vaccine without parental permission. Should we try to change the laws? Silverman and colleagues, writing in the New England Journal of Medicine, suggest that we should. In their opinion, adolescents should not be harmed by laws that allow parental decisions that are contrary to the teen's own desires when the teen wants a treatment that is safe, effective and recommended by both pediatricians and public health officials. Permitting teens to consent, they write, “... promotes the minor's health, poses minimal personal risk, and offers substantial prosocial benefits, including reinforcement of the norm of vaccination and enhancement of community protection against the spread of dangerous and costly yet preventable diseases." They go on to state, "Given such benefits, we believe that states should enact laws that expand both access to vaccines and the rights of minors who are at least 12 to 14 years of age to consent to vaccination" 6 .

\section{References:}

1. WHO (World Health Organization). Considerations regarding consent in vaccinating children and adolescents between 6 and 17 years old. World Health Organization. 2014. Available from:

https://apps.who.int/iris/bitstream/handle/10665/259418/WHO-IVB-14.04-eng.pdf?sequence=1\&isAllowed=y (accessed 20.05.2021)

2. Skiles M, English A, Cai J, Agans R, Koumans E, Stokley S et al. Minor Consent and Delivery of Adolescent Vaccines. J Adolesc Health. 2010; 46(2): S71.

3. Sundaram N, Voo T, Tam C. Adolescent HPV vaccination: empowerment, equity and ethics. Hum Vaccin Immunother. 2019; 16(8): 1835-1840.

4. Skiles M, English A, Cai J, Agans R, Koumans E, Stokley S et al. Minor Consent and Delivery of Adolescent Vaccines. J Adolesc Health. 2010; 46(2): S71.

5. Can a 16-year-old get a COVID-19 vaccine without parental consent? News Break. 2021 [cited 29 April 2021]. Available from: https://www.newsbreak.com/news/2190317907208/can-a-16-year-old-get-a-covid-19-vaccinewithout-parental-consent (accessed 20.05.2021)

Journal of Shalamar Medical and Dental College. 2021; Vol. 2 (1) 
6. Silverman R, Opel D, Omer S. Vaccination over Parental Objection - Should Adolescents Be Allowed to Consent to Receiving Vaccines? N Engl J Med. 2019; 381(2): 104-6.

\section{Corresponding Author:}

Prof. John D. Lantos

Department of Pediatrics

Glasnapp Family Foundation Endowed Chair in Bioethics

Director, Children's Mercy Bioethics Center

Children's Mercy Hospital

Kansas City UMKC School of Medicine 2401 Gillham Road |

Kansas City, MO 64108, USA. 